\title{
Research on Business Process Management of Engineering Cost Consulting Enterprise
}

\author{
Liming Xia ${ }^{\mathrm{a}}$, Nan Lin ${ }^{\mathrm{b}}$ and Yue $\mathrm{Li}^{\mathrm{c}}$ \\ School of Management, Tianjin University of Technology, Tianjin 300384, China \\ a496239475@qq.com, b linnantongxue1990@163.com, c1244747319@qq.com
}

\begin{abstract}
Keywords: business process; process management; integrated management; interface management.
\end{abstract}

\begin{abstract}
Nowadays, the competition in the engineering cost consulting industry is becoming more and fiercer, and how to distinguish the cost consulting company from the industry is a subject worthy of further study. In this background, from the Angle of the consulting enterprise, introducing process management cost Consultation Company in the process of knowledge management, the consulting business process design, make its form a standardized system, which will consult the business process efficiency, the enhancement enterprise's core competitiveness. Therefore, if enterprises want to implement effective management, they must find a point of entry and integrate into the business process of the enterprise so as to produce good results. Therefore, this study believes that the enterprise should take the key business as the breach of the implementation management, and find the integrated management method of the business process. In addition, compared with the overseas engineering cost consulting enterprises, the gap between China's cost consulting companies and the urgent development demands are particularly prominent, and it is imperative to achieve a thorough transformation.
\end{abstract}

\section{Introduction}

This paper discusses how to introduce process management related research to redesign the business process of engineering cost consulting enterprise.

In recent years, process management has become a hot research topic and the main content of process management. The main research contents are process design, process implementation, process monitoring and process optimization. This study looks at business processes from a process management perspective and standardizes them, then establishes an integrated management model.

\section{Key Concept Definition}

\subsection{Business Process}

"Process", in the Oxford English dictionary, is interpreted as "one or a series of actions, in some manner or execution, to achieve a particular result", also called a Process. In the field of management science, business processes are generally considered to be used when the research object is a process. The term "business process" also has a number of definitions. Here are some typical examples:

1. The business process by which Michael Hammer acquiesces is to transform one or more inputs into valuable outputs.

2. T. H. Davenport proposes that a business process is a collection of measurable structured activities that produce corresponding outputs for a particular market or specific customer.

3. ISO9000 defines the business process as a series of interrelated or interactive activities that translate input into output.

4.The Butler Group, points out that in order to achieve the goal of an established and carried out a series of tasks or activities, is called business process, these activities can be internal or external, or system, according to the specific order to be complete.

Because the emphasis is different, produce the different ways to define, but we have these definitions found in the common area, summarized the elements of a business process is obtained: the 
input resources, activities, activities and activity, output, customer relationship and value of the output. We can also find that the process has the following characteristics:

1. Purpose: the process has a clear goal, which can be a satisfactory service and so on.

2. Immanence: there are processes in anything or action.

3. Integrity: the process consists of at least two interrelated activities. Literally, the process has a "flowing" meaning.

4. Dynamics: the process is carried out in a certain order, one activity is completed, and the next activity begins, so it is not a static concept.

5. Hierarchy: the process is a nested concept, and some activities in the process can be considered as "sub-processes" and continue to decompose into several activities.

6. Structure: series, parallel, feedback and circulation are all expressions of the process. As a result, processes have multiple forms of expression, and the use of different structures will result in different process effects.

To sum up, this study finds the intrinsic nature of business processes and summarizes the following:

1. Business process refers to the interaction between different departments and different personnel;

2. The purpose of business process is to create value for customers;

3. Each organization according to its function, divided into specific functions performed by each organization, but a separate department is not create value for enterprises, enterprises should do is to put the activity of transverse cutting in the process of the business department.

As the core component of modern enterprise management system, the business process cannot be separated from reasonable process. All activities through the process of the different combination and coordination, the efficiency and effect of process is not the same, if the business process includes many value-added or unnecessary activities, will inevitably affect the process of the performance of the overall implementation. A successful enterprise must have a reasonable work flow and a reasonable business process that requires good business process management. In the process of enterprise transformation or expansion, new business process design can be carried out according to the actual needs of the company.

\section{Process Management}

The concept of process management was first proposed in the mid to late 1990s, and the idea of process management had already appeared before that.1911, Frederick Taylor in his book "the principles of scientific management, this paper expounds the thought is embodied in the process of practice and policy manual work, but did not form the concept of process management, but it is called" method and process analysis. In the 1980s, it was proposed to combine the idea of Process Management with quality Management. In 1988, IBM's Process Management was officially named BPM (Business Process Management).In order to echo the enterprise business Process reengineering, BPR, in 1991, changed it to Process Management.1993 Michael hammer and James carlo azeglio ciampi jointly published "reengineering the corporation", in the book of the elements of enterprise business process reengineering is defined, is a process, fundamental, thoroughness and significance, and systematically for the first time an explanation to the theory of business process reengineering. As a part of the management itself, the process management in the scientific management and the backdrop of the rapid development of management science, and natural germination and development of a series of process management methods and techniques also appeared, these methods and techniques have been improved and perfected.

Through a large number of literature reading and the study of knowledge, it is not difficult to find that an important part of business process management is the process reengineering, but there are a lot of people think that process management is the process reengineering, this claim is not objective, is one-sided. At present, many scholars in China have explained the process management and process reengineering from different perspectives. Guoqing Huo said, for example, the enterprise business 
process reengineering is the fundamental, the change of enterprise's operation mode, so as to realize enterprise goal, it emphasizes that enterprises should do next, task is to find a creative way, make the enterprise change significantly. As a methodology, business process reengineering is a long-term and global perspective, highlighting the concept, concept and concept of development and cooperation[1].Shusheng Sun thought, such as business process reengineering is not a simple division of refute the traditional business process reengineering theory, the traditional enterprise internal organization of division of Labour between lateral department communication difficulties, lead to low efficiency and high cost of business activities, is not conducive to the long-term development of the enterprise, to facilitate the process oriented enterprise organization form different personnel division of labor and cooperation, maintain, in good faith on the basis of division of labor, for the customer, enterprise and employee goals more unified[2].

\section{Research on Process Management.}

Now, in the research of the concept of process management, but the definition of the concept and main content, the end of the academic circles have not unified, but in general, all process management, including process design, process execution, process diagnosis of the whole process of the content, process reengineering and optimization process redesign of process management and activities of life cycle. It is developed by the theory of business process reengineering. There are two main ways to divide the development stage of process management. Firstly, the process is divided into the following aspects according to the content of the process and the method of implementation. The other is the process of division of technology.

The first view is classified according to the content of the process and the implementation method. For example, Jian Wang and others believe that there are three stages of process management, as shown in the following Table One:

Table 1 Phases for Process Management.

\begin{tabular}{|c|c|c|}
\hline Stage & Content & Representative personage \\
\hline $\begin{array}{l}\text { Traditional production process } \\
\text { period. }\end{array}$ & $\begin{array}{l}\text { The division of labor theory lays } \\
\text { the foundation for the process } \\
\text { management and the practical } \\
\text { application of process management } \\
\text { represented by the production line. }\end{array}$ & $\begin{array}{l}\text { Adam Smith; } \\
\text { Taylor. } \\
\text { Henry fayol. }\end{array}$ \\
\hline Reengineering period & $\begin{array}{l}\text { The BPR theory emphasizes } \\
\text { revolutionary, radical and significant } \\
\text { overall transformation. }\end{array}$ & $\begin{array}{l}\text { Michael hammer; } \\
\text { James money; } \\
\text { Davenport, }\end{array}$ \\
\hline Process management period & $\begin{array}{l}\text { BPM theory, which introduces } \\
\text { process optimization and } \\
\text { improvement into process } \\
\text { management, emphasizes the lifecycle } \\
\text { management of processes and the } \\
\text { application of information technology. }\end{array}$ & \\
\hline
\end{tabular}

In conclusion, the above theoretical knowledge provides a rich theoretical basis for how to conduct process management and broadens the research perspective.

BPR (Business Process Reengineering) has always been a hot topic in the field of enterprise and management science. It has been translated as: Business Process Reengineering, enterprise Process Reengineering. Business process reengineering theory in 1990 by the famous enterprise management master Mr Michael hammer is proposed for the first time, after the theory introduction, some such as IBM, ford, represented by large companies begin to implement BPR, want to make through process reengineering their enterprise development. As a result, after the implementation of BPR, these large enterprises have undergone tremendous changes and achieved great success. Michael Hammer and James Champy is defined as to the process reengineering of the enterprise business process 
reengineering fundamentally reconstruct the business process, cost, quality and service, and significantly higher in speed, make enterprises maximize meet customer is characterized by competition, change of the modern business environment.

BPR has gained the attention of the world because of its unique advanced nature and the thoroughness of change and the significance of the effect. Business process reengineering, more from the perspective of process activities, through business processes to express the design of the process. In today's information network and knowledge economy era, the organization should invest significantly to improve the efficiency of production efficiency and knowledge resources to improve the commercial value of creativity. However, the research is limited to the understanding of business process design and the lack of analysis of the role of organizational structure[3].With the implement of knowledge flow process reengineering, eliminates the knowledge management model for process reengineering independent adverse effect, more conducive to knowledge process and the interaction between the business process, improve business efficiency. Therefore, the business process and business process reengineering based on knowledge flow research not only have theoretical significance, but also have practical guidance to guide business process reengineering.

Purpose of business process reengineering from the Angle of the system of enterprise internal work, put in a business process is invalid links and repeat process redesign, to simplify the process, improve the efficiency of the enterprise business.

In this study, the optimization of knowledge flow in the selection of business reorganization theory has the following considerations:

Firstly, this theory provides theoretical basis for selecting process management as the perspective of this research. Process is essentially a value chain in a series of interdependent and interrelated activities, this research is to study the interaction relations between the two processes, so that the content of the need to integrate management is more rich, difficulty also multiplied. This is where you need to reorganize the processes that are duplicated or fail to generate incremental value, which greatly reduces the difficulty of integration management.

Secondly, there is a clear interpretation of business reorganization theory, which fully demonstrates the feasibility of business reorganization theory in knowledge management.

Although the theory of enterprise process reengineering is instructive and transformational, it is realized by means of process optimization in practice.

Process optimization is a method to maintain the competitive advantage of the enterprise by continuously developing, perfecting and improving the business process of the enterprise. It's not just about doing the right thing, it's about doing the right thing.

Process management in Taylor's scientific management thoughts began to sprout, 100 over the years, through continuous development, has become a mature management thought and method, process management has become the mainstream of management thoughts in the developed countries.

This study thinks that process management is a systematic management approach, respectively for knowledge process and business process optimization and improvement, to get more suitable process, so as to improve the efficiency of the enterprise operation, reduce the spending extra cost.

\section{Study on Process Design}

\subsection{Theory and Application Principle.}

Process design is a method to solve problems, and its main task is to solve various problems in the design process, including proposing, analyzing and solving problems. During this period, there are two main problems: the first one is design requirements, the second is knowledge utilization, and the problem is how to design.

Process design refers to the process of achieving a certain goal in the whole design process, and the final design output is the process. The main components of process design are process design process and process design method. Among them, in the design process, the current research is more standardized and mature, whether BPR or BPM, in this respect, there are a lot of research results. 
Process design method mainly includes the modeling of the evaluation of core technology and process modeling technology, mainly used for the description and the analysis process, process evaluation model of the evaluation, to determine the final design results. Process modeling technology is the key and core of process design.

At present, the study of process design procedure is relatively standard. Basically, they are based on the life cycle approach, and phase task techniques, analysis and synthesis. Although the method is different, there is no standard method, but the steps can be divided into concepts, starting, diagnosis, design, implementation and evaluation.

1. The design scheme in the process of research, typically include: comprehensive S - A BPR model, this model is based on 25 kinds of process reengineering, process reengineering methodology provides A complete framework, defines the basic tools as the main work of every step, can be used to represent the law of life cycle's specification[4].

In addition, the spiral model of BPR proposed by zhang yuandong. In fact, life cycle method and iterative method combine to form the design process of continuous optimization and continuous improvement [5].

2. Research on process modeling technology.

At present, process modeling technology is mainly embodied in method system level and technical tool level. The method system provides a comprehensive technical tool, the application method of technical tools, and provides specific modeling tools.

Modeling method of the current mainstream system basically has the following models: IEM, ARIS system and GRAI/GIM method, CIM - OSA, Purdue enterprise reference architecture (GERAM PERA) method, and the Zachman box, other framework, IBM's enterprise overall architecture framework, UML modeling framework.

\subsection{Applicability Analysis.}

At present, from the perspective of domestic business processes, it is reasonable to design the process from the perspective of integration to make the new process more targeted. In establishing the model, this study adopts the method of flowchart, which is easy to operate and has no harsh conditions, and the flowchart is easy to analyze.

\section{Engineering Cost Consulting Enterprise Business Process Design}

During the design process, brainstorm method and brainstorming method can be used to give full play to the creative thinking, discuss with each other, and boldly imagine that the procedures of 3 to 5 will be reviewed by the expert group. New technology in the process of project review on technology choices to consider (efficiency) and cultural habits and the ability of (employees) two factors, the particular way is: from each project evaluation of the process view technology, the most effective, determine each business process, find out the gap between each scheme and the enterprise culture, eliminating the cost evaluation of the gap between the (time, money, the cost of interpersonal relationship, etc), according to two assessment. The comprehensive consideration of the optimal scheme [6], meanwhile, should draw on the successful experience of other industry business process reengineering, and absorb the advantages of each project to make it a more satisfactory project.

According to the above steps, a new business process design of engineering cost consulting enterprise based on full life cycle was conducted, and the process design of the business process as shown in Figure One: 


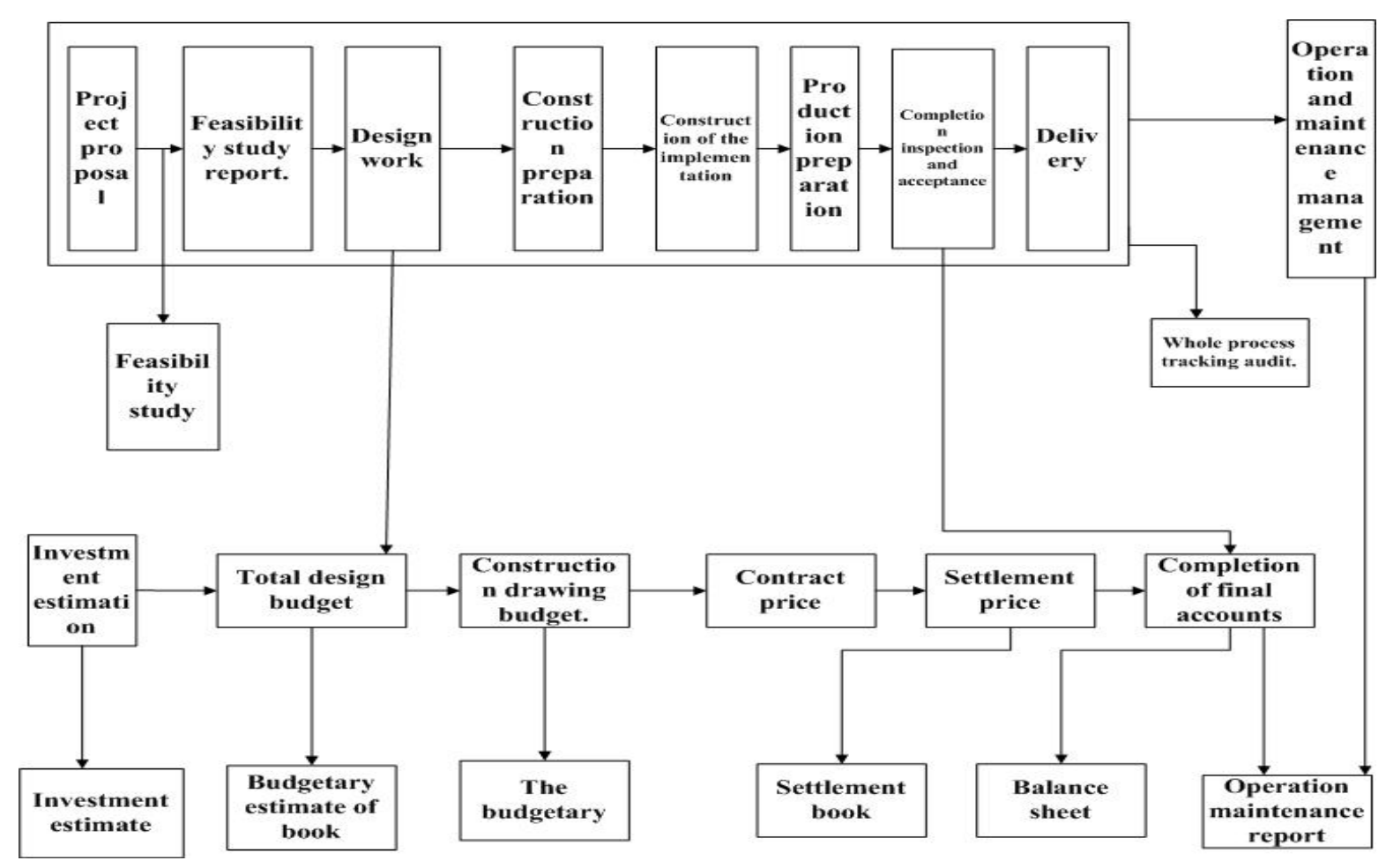

Figure 1 Engineering Cost Enterprise Business Process.

\section{Summary}

In this study, the process management is the main research framework, combined with the method of process design and process reengineering, the business process of engineering cost consulting enterprise is constructed and the integrated management model is established. The main conclusions are as follows:

1. In order to survive in the fierce competition in the information age, traditional engineering cost consulting enterprises must realize the importance of process management. Through process management, the process can be improved and optimized, and the process can be carried out efficiently.

2. Engineering cost consulting business process flow can be coupled with the knowledge that in the middle on the edge of the medium is knowledge, it includes the business before the business knowledge, also includes the operations of knowledge, knowledge is derived from the business, service in the business.

\section{References}

[1]. Zhongjin Guo. The origin, evolution and development trend of business process reengineering theory [J]. Modern management science, 2007(11):8-9.

[2]. Shusheng Sun, Wenjiang Tian. Based on management integration of BPR [J]. Technology and management, 2002, 4(4):60-62.

[3]. Yin Gai. Business process design method based on process knowledge [J]. Science and technology and engineering, 2011, 11(29):7202-7207.

[4]. Process reengineering: theory, method and technology [M]. Tsinghua university press, 2004.

[5]. Yuandong Zhang. Study on the knowledge rule system of computer aided business process reengineering system [D]. Shandong University, 2008.

[6]. Song Li, Na Gao, Ning Wang. Evaluation of the effect of business process reengineering and continuous improvement of process [J]. Industrial technology economy, 2006, 25(10):86-89. 